\title{
BNCC, CURRÍCULO DE SERGIPE E DIVERSIDADE: UM LUGAR AINDA DESTINADO À BIOLOGIA?*
}

\author{
Tássia Alexandre Teixeira Bertoldo \\ Ann Letícia Aragão Guarany \\ Lívia de Rezende Cardoso
}

\section{Introdução}

Nos últimos anos, os debates em torno das diversidades, das quais destacamos as de gênero e sexualidade, nas políticas públicas educacionais no Brasil vêm ganhando protagonismo. Isso se deu principalmente com as discussões suscitadas na aprovação do Plano Nacional de Educação (20142024), da Base Nacional Comum Curricular (2017) e da Base Nacional de Formação de Professores (2019), documentos permeados por discursividades atreladas às racionalidades conservadora e neoliberal (CARDOSO et al., 2019; PIRES, CARDOSO, 2020). Tal protagonismo se evidencia, igualmente, nos processos de elaboração dos currículos estaduais e municipais para a educação básica, quando apontam para um retrocesso em torno da diversidade e da diferença na constituição dos sujeitos e uma concepção de gênero que retoma a defesa de uma naturalização da constituição de homens e mulheres.

Em nossas pesquisas sobre currículos e atuações como educadoras, dialogamos com o campo multicultural que busca evidenciar os processos de sujeição, dominação e resistência em culturas específicas. Inspiramonos, para isso, em estudos foucaultianos, feministas e teorizações queer. Nesse sentido, operamos com o conceito de diversidade, sobretudo de gênero, corpo e sexualidade, a partir de uma perspectiva pós-moderna. Colocamos em suspeição as microrrelações de poder, os universais antropológicos, a descorporificação da consciência, a racionalidade científica e as práticas normativas que constituem o sujeito da modernidade. Questionamos dimensões de gênero, corpo e sexualidade das subjetividades almejadas em currículos de ciências naturais.

Entendemos gênero como uma espécie de maquinaria, apoiada em diferentes discursos que circulam culturalmente, que criam sujeitos espe-

"DOI - 10.29388/978-65-86678-66-6-f.55-72 
cíficos de uma sociedade (LAURETIS, 1994). É preciso, nessa compreensão, separar gênero da diferença sexual e da sexualidade para entendê-lo como produto de variados discursos. Desse modo, articulamos o que diz Teresa de Lauretis com as problematizações feitas por Judith Butler (2010a), buscando desnaturalizar o sistema sexo/gênero/sexualidade. Esse sistema foi objeto das análises de Michel Foucault, especificamente o que ele denominou por dispositivo da sexualidade, que consistiu em "reduzir o sexo à sua função reprodutiva, à sua função heterossexual e adulta e à sua legitimidade matrimonial" (2010, p. 114) com o advento de um projeto biopolítico de modernidade.

A partir desses conceitos, buscamos compreender como construções de gênero e sexualidade são abarcadas no âmbito educacional e, sobretudo, em currículos de ciências e biologia por considerarmos que esses currículos foram sempre vistos como privilegiados para abordar tais questões. Nosso objetivo é, mais especificamente, analisar como a diversidade de gênero e sexualidade é proposta no Currículo de Sergipe, documento construído a partir da formulação da BNCC (2017). Corazza (2001) justifica a análise de currículos formais e oficiais por entender o discurso curricular com função governamental, que inscreve formas de ação sobre as condutas e relações individuais e coletivas, habilitam os indivíduos a viverem tipos particulares de experiências e a se tornarem determinados tipos de sujeitos, para atingir certos objetivos sociais e políticos.

Partindo desses pressupostos, questionamos: a Biologia ainda é o lugar das discussões de diversidade de gênero e sexualidade? Para desenvolvê-la, trazemos na próxima seção um breve contexto histórico da produção do Currículo de Sergipe de um modo geral para os diferentes níveis de ensino. Em seguida, apresentamos análises dos textos introdutórios do currículo e do componente curricular de Ciências e Biologia, além dos objetos de conhecimento e habilidades previstas para os componentes biológicos. Por fim, tecemos algumas argumentações a partir dos estudos empreendidos acerca desse currículo e suas implicações na produção de subjetividades.

\section{Construção da BNCC e do Currículo Sergipano}

Em 1996, com a homologação da Lei de Diretrizes e Bases da Educação Nacional (LDB), se instituiu a política educacional brasileira (BRASIL, 
1996), delimitando que a organização e administração da educação ficariam a cargo de cada nível de governo. No tocante às questões de gênero e sexualidade, a LDB não trouxe explicitamente normas que discutissem e muito menos problematizassem as construções de gênero.

Os Parâmetros Curriculares Nacionais (1998) trouxeram orientações por área em vários cadernos, tornando-se um marco nas questões de diversidade. Incluíram um volume que tratou especificamente da temática da diversidade sexual, sobre o qual Nardi (2008) aponta a recomendação da transversalidade em todas as disciplinas e articulação da temática da orientação sexual e relações de gênero com outros temas, como ética, saúde, ecologia e pluralidade cultural. Posteriormente, o primeiro Plano Nacional de Educação (BRASIL, 2001) foi aprovado com a garantia da organização de currículos que assegurassem a pluralidade da identidade do povo brasileiro, o desenvolvimento da cidadania, as diversidades regionais, étnicas e culturais entre suas diretrizes gerais.

Alguns outros instrumentos legais foram aprovados posteriormente neste sentido da inclusão, dos quais podemos destacar a Lei no 12.796 , de 2013 junto com a Lei 11.645 de 2008 que incluem a obrigatoriedade da temática História e Cultura Afro-Brasileira e Indígena e as Diretrizes Curriculares Nacionais: para a Educação das Relações Étnico-Raciais e para o Ensino de História e Cultura Afro-Brasileira e Africana em 2004; para a Educação em Direitos Humanos; para a Educação Escolar Quilombola na Educação Básica; para a Educação Escolar Indígena na Educação Básica e para Forma ção de Professores Indígenas, todas em 2012.

$\mathrm{Na}$ atualização do $\mathrm{PNE}$, vemos alguns retrocessos ganharem espaços e tomar formas na composição das metas do atual plano decenal de Educação. A progressão dos debates sobre a educação para as relações de gênero despertaram várias críticas e ataques, gerando tensionamentos e modificações na redação final do PNE (BRASIL, 2014), que se disseminou nas discussões em torno dos Planos Municipais e Estaduais de Educação. Esses ataques ao que chamam "ideologia de gênero" partiram de movimentos conservadores e promoveram um pânico moral por defenderem que essa suposta ideologia fere a dignidade do matrimônio, o respeito ao direito à vida e a constituição da família (JUNQUEIRA, 2017).

A proposição da existência de uma "ideologia de gênero" não corresponde ou resulta do campo dos Estudos de Gênero ou dos movimentos feministas e LGBTQIA+. Ainda de acordo com Junqueira (2017), é uma invenção católica que surgiu no Pontifício Conselho para a Família e de confe- 
rências episcopais, entre a década de 1990 e no início dos 2000. O uso do termo "viralizou" nos anos seguintes dentro das manifestações conservadoras, que no Brasil está bastante ligada também às igrejas evangélicas, contra políticas sociais, reformas jurídicas e ações pedagógicas que pudessem promover os direitos sexuais, enfrentar preconceitos, prevenir violências e combater discriminações.

Esses embates merecem destaque na discussão deste capítulo, pois representam o cenário vivido nos últimos anos e que influem diretamente na composição das Políticas Públicas Educacionais atuais e nos respectivos documentos oficiais, entre eles no Currículo Sergipano que analisamos. Em meados de 2017, o MEC entregou a última versão da Base Nacional Comum Curricular (BNCC) ao Conselho Nacional da Educação (CNE). A BNCC, no entanto, chegou aos conselheiros com alterações, dentre elas foram retirados os termos "gênero" e "orientação sexual" de trechos específicos. A versão anterior a esta, por sua vez, estabelecia como um dos objetos de conhecimento "[...] corpo, gênero e sexualidade nas tradições religiosas" e definia que as escolas deveriam "[...] discutir as distintas concepções de gênero e sexualidade segundo diferentes tradições religiosas e filosofias de vida" (BRASIL, 2016, p. 29).

Após discussões entre 22 conselheiros, 19 votaram pela retirada das temáticas. Assim, deixaram de compor os objetos de conhecimento do documento final sendo incluído o eixo "princípios e valores éticos", que tem como umas das habilidades "[...] reconhecer a coexistência como uma atitude ética de respeito à vida e à dignidade humana" (BRASIL, 2016, p. 459). As alterações e exclusões afetaram também as competências gerais e habilidades para as Ciências Naturais.

Encontramos na BNCC o reconhecimento à diversidade e a importância da valorização, do acolhimento e do respeito às diferenças, principalmente citando a diversidade humana e cultural. A diversidade no documento remonta saberes e vivências culturais, conhecimentos e experiências, escolhas alinhadas ao exercício da cidadania e ao seu projeto de vida, assim os alunos devem se fazer respeitar e promover "o respeito ao outro e aos direitos humanos, com acolhimento e valorização da diversidade de indivíduos e de grupos sociais, seus saberes, identidades, culturas e potencialidades, sem preconceitos de qualquer natureza" (BRASIL, 2018, p.10).

Nas competências específicas para as Ciências Naturais, a diversidade se coloca como aspecto étnico e cultural humano a ser valorizado e respeitado na aplicação dos princípios da evolução biológica e no cuidado com 
o uso indevido de conhecimentos das Ciências da Natureza na justificativa de processos de discriminação, segregação e privação de direitos individuais e coletivos, em diferentes contextos sociais e históricos, para promover a equidade e o respeito à diversidade. Formas de viver o gênero e a sexualidade não se colocam como expressão de identidade, marcador de diversidade ou traço de diferença.

A palavra gênero na BNCC aparece apenas como textual, discursivo, literário jornalístico, publicitário entre outras caracterizações ligadas às linguagens, não da forma que discutimos. Já sexualidade aparece nos anos finais do ensino fundamental e apenas na área de Ciências Naturais relacionado à reprodução e no autocuidado com o corpo na perspectiva de saúde sexual e reprodutiva. Assim, é elencado o objeto de conhecimento "mecanismos reprodutivos e sexualidade" a partir do qual estudantes devem ser hábeis em comparar os diversos métodos contraceptivos, para escolher o método mais adequado à prevenção da gravidez precoce e indesejada e de Doenças Sexualmente Transmissíveis (DST). Entre as habilidades, está também a seleção de argumentos que evidenciem as múltiplas dimensões da sexualidade humana (biológica, sociocultural, afetiva e ética).

Percebemos como a dimensão da sexualidade na BNCC está restrita ao trinômio corpo/saúde/doença e à educação sexual, que desta vez se dirige ainda mais ao autocuidado e ao exame de si mesmo como forma de autogoverno numa perspectiva higienista. O campo da Biologia para a BNCC continua a ser o lugar da sexualidade humana nos conteúdos escolares, desde que restrito a esses aspectos, já as relações de gênero não encontram espaço nem mesmo aí como se as características biológicas sexuais encerrassem toda a discussão de gênero.

A importância e a preocupação em manter esses termos nos documentos devem-se aos efeitos que a ausência dessas expressões pode produzir, dentre eles, uma visão reducionista do assunto. Segundo Junqueira (2017, p. 26), corre-se o risco de "[...] promover uma restauração do estatuto da ordem sexual tradicional e reforçar as disposições relativas às normas de gênero, à heterossexualidade obrigatória e à heteronormatividade". Essas alterações acabaram repercutindo nos planos municipais e estaduais de Educação, que deveriam prever o que seria da área nos próximos dez anos.

Importante destacar que para analisar políticas da educação é preciso compreender, como apontado por Cardoso et al. (2019), sua importância dentro do projeto social de Estado que está sendo implementado, pois as alterações no currículo oficial nacional ao longo das três últimas décadas 
expressaram os conflitos na arena política. Enquanto evocavam por uma formação democrática, também carregaram a regulamentação de propósitos educacionais que atendessem ao mercado privado e aos parâmetros internacionais de eficiência travestidos em competências e habilidades. Foi nesse cenário e contexto que ocorreu a aprovação do Currículo de Sergipe o qual nos propomos a analisar neste trabalho.

Após a homologação das etapas da Educação Infantil e Ensino Fundamental, em dezembro de 2017, a BNCC tornou-se o documento normativo que se autodefine como "o conjunto progressivo de aprendizagens essenciais que todos os alunos devem desenvolver ao longo da Educação Básica" (BRASIL, 2017, p. 5). Em 2018, em todos os estados brasileiros, deu-se início a reelaboração das Diretrizes Curriculares Estaduais. Não diferente disso, nosso estado iniciou a formulação do chamado Currículo Sergipano. Após as fases denominadas de Consultas Públicas e Seminários "Dia D", em dezembro de 2018 o Currículo de Sergipe é homologado. Neste mesmo período a BNCC para o Ensino Médio é homologada e em 2019, iniciou-se processo de elaboração de uma proposta para o currículo de cada estado e em 2020, etapas semelhantes às do ensino fundamental ocorreram. Porém, o documento aguarda aprovação do Conselho Estadual de Educação para homologação, que foi prevista para dezembro desse mesmo ano.

\section{Diversidade no Currículo Sergipano}

Como discutem Macedo e Ranniery (2018) ao analisar os endereçamentos das políticas públicas, a ampliação dos pontos de identificação vem tornando a tarefa de endereçar o outro como um sujeito abstrato cada dia mais difícil. Seguindo essa ideia, o emaranhado de seres e de vidas, nunca plenamente formados, sempre constituídos em relação, pode permitir a rearticulação das políticas em educação para o desfazer do cidadão humano trabalhador abstrato e tornar cada vez mais, mas nunca permanentemente, problemáticos os compromissos das políticas curriculares com a normatividade.

Porém, Rodrigues e Abramowicz (2013) afirmam que a diversidade nas políticas educacionais acabou por ser entendida como uma forma de governamento exercido pela política pública no campo da cultura, como estratégia de apaziguamento das desigualdades e de esvaziamento do campo da diferença, considerando que a diferença teria como função borrar identi- 
dades e quebrar hegemonias. Assim, corroborando Silva (2010), uma perspectiva que se limite a afirmar a existência da diversidade não pode servir de base para uma pedagogia que coloque no seu centro a crítica política da identidade e da diferença. Pois nesse sentido, a diferença e a identidade tendem a ser naturalizadas, cristalizadas, essencializadas como dados ou fatos da vida social diante dos quais se deve tomar posição, no caso de tolerância ou respeito.

O Currículo de Sergipe garantiu a inclusão das temáticas de diversidade de gênero e sexualidade, mas está pautado na perspectiva de reconhecimento, naturalização e apaziguamento. Esse currículo afirma ter como base oito princípios norteadores, sendo eles: Colaboração, Respeito à diferença, Criticidade, Inclusão, Equidade, Autonomia, Sustentabilidade e Criatividade. Sobre Respeito à diferença, é dito: "Saber lutar, combater a discriminação e o preconceito que afetam a autoestima do estudante, isso se reflete no aprendizado e pode ser uma das causas da desistência do aluno. É uma atitude que precisa ser encampada pela coletividade, não é uma responsabilidade só de quem é discriminado, a escola precisa ser o espaço que proporcione a reflexão e mudança de postura" (p. 11). O princípio Inclusão seria: "Participar da garantia do direito de todos à educação. Concretiza-se na igualdade de oportunidades e a valorização das diferenças humanas, contemplando, assim, as diversidades étnicas, sociais, culturais, intelectuais, físicas, sensoriais e de gênero dos seres humanos" (p. 11).

Silva (2000, p. 99) chama atenção para pensarmos diversidade e diferença como uma estratégia que compreenda e assuma o fato de a diversidade não conseguir "fornecer os instrumentos" que questionem a destinação das pessoas em determinados grupos, fixando-as "em determinadas identidades culturais e que as separam por meio da diferença cultural". Antes de apontar o respeito e a tolerância é preciso deixar claro como a diferença é produzida e para isso é preciso uma política pedagógica e curricular da identidade e da diferença que tenha "a obrigação de ir além das benevolentes declarações de boa vontade para com a diferença" (SILVA, 2000, p. 99), como o Currículo de Sergipe aponta ao conceituar os princípios dois e quatro.

Ainda na Introdução, afirma-se, dentre tantas diversidades citadas, que se deve "reconhecer a dimensão histórico-social das construções de gênero e de orientação sexual, do mesmo modo, as implicações dos processos culturais de "normatizações" (p. 28). Logo em seguida, há a ressalva de que: 
Os modos de estar no mundo demarcam uma estética, uma ética, uma posição política, mesmo quando não se tem consciência disso. Não compete ao projeto escolar, em temas sensíveis como sexualidade, gênero e religiosidade defender esse ou aquele caminho. Aos educadores, fica a tarefa de organizar e coordenar ambientes de aprendizagens que oportunizem às crianças e aos adolescentes o desenvolvimento da autoestima, o respeito por si e pelo outro, independente das travessias subjetivas que todo cidadão tem o direito de realizar, devendo, inclusive, intervir dentro dos parâmetros e dos propósitos educacionais, para que a caminhada de cada um não coloque mediante risco a dignidade de si e dos que, ao lado, fazem também sua jornada (p. 29).

É possível observar a tentativa de reduzir as possibilidades de discussões apenas à condição de respeito e tolerância, quando se parecia reconhecer a existência de normas de comportamento. Além disso, joga para a individualidade as "travessias subjetivas" e enfoca no "risco a dignidade" a chance de gerar um certo silenciamento por medo da indignação ou desrespeito a alguém. Cardoso (2012) chama atenção para o fato de essas formas acabarem disfarçando que os currículos já são produzidos por discursos generificados e heteronormativos.

Em uma busca geral pelo termo "gênero" no documento, encontramos 259 indicações. Destas, 3 foram encontradas no componente Educação Física, 1 em Língua Inglesa, 1 em Geografia, 1 em História e 2 em Ciências da Natureza. Todas as outras referiam-se a gêneros textuais. O termo "muIher" foi encontrado em 15 situações, sendo 2 em Educação Física, 3 em Geografia, 4 em História e as outras em contextos que não se referiam a conteúdos do currículo. O termo "feminino" ocorreu 10 vezes e teve distribuição semelhante ao termo anterior, enquanto o "masculino" apareceu apenas 2 vezes e no componente Educação Física. Para o termo "sexual", foram encontrados 13 locais, sendo 4 na Introdução do documento, 1 na Introdução do componente Matemática e todos os outros em conteúdos de Ciências. Para o termo "Diversidade", a busca indicou 114 resultados, dos quais 20 estavam na Introdução do Documento, 5 em Artes, 8 em Educação Física, 15 em Língua Inglesa, 2 em Língua Portuguesa, 7 em Geografia, 11 em História, 7 em Ciências Naturais, 2 em Matemática e 13 em Ensino Religioso. Em 26 situações desse total, o termo diversidade foi empregado para outras conotações que não a diversidade cultural. 
Evidenciamos que discussões em torno das construções de gênero, sexualidade e diversidade não são exclusividades, portanto, das ciências naturais ou dos saberes biológicos. Há um avanço, sobretudo na área de Humanidades, em apontar questões como a história de movimentos sociais, a luta do feminismo, embates culturais entre gêneros, a ausência ou presença das mulheres na política e na história. Essas discussões em disciplinas específicas sinalizam uma atualização dos conteúdos a partir do que vem sendo recomendado por pesquisas feministas sobre a produção dos conhecimentos pelas ciências (MATOS, 2008).

Nas Competências Específicas das Ciências Naturais, a competência 7 indica a necessidade de "Conhecer, apreciar e cuidar de si, do seu corpo e bem-estar, compreendendo-se na diversidade humana, fazendo-se respeitar e respeitando o outro, recorrendo aos conhecimentos das Ciências da Natureza e às suas tecnologias" (p. 472). Nos Objetivos, segundo esse documento, busca-se "estimular o estudante por meio da prática da investigação científica e ampliar a visão de si e dos seres vivos e interação com o ambiente e seus fenômenos naturais" (p. 477). Afirma ainda que, a medida que avançam nos anos escolares, "percebem-se uma ampliação progressiva da capacidade de abstração e da autonomia de ação e de pensamento, em especial nos últimos anos, e o aumento do interesse dos alunos pela vida social e pela busca de uma identidade própria. Essas características possibilitam a eles, em sua formação científica, explorar aspectos mais complexos das relações consigo mesmos, com os outros, com a natureza, com as tecnologias e com o ambiente; ter consciência dos valores éticos e políticos envolvidos nessas relações; e, cada vez mais, atuar socialmente com respeito, responsabilidade, solidariedade, cooperação e repúdio à discriminação" (p. 478-479).

Nesses trechos, há um apelo à aplicação dos conhecimentos científicos nas vidas sociais e na constituição de percepções sobre si mesmos/as, de modo responsável para consigo e com os outros. Quando apresentados assim, sem uma contextualização do processo de produção da ciência, através de conteúdos aparentemente neutros e não intencionados, o ensino dos conhecimentos científicos pode contribuir para o governo das condutas no sentido de perpetuação de desigualdades de gênero e padronização de corpos e sexualidades (CARDOSO, 2018). Como se daria esse processo reflexivo e de tomada de decisões suscitado por esse currículo sem o exercício de problematizar práticas e saberes normativos que permeiam a ciência? 
A crítica feminista às ciências biológicas, mesmo proveniente de diferentes vertentes, considera-as uma produção de seus/suas criadores/as e, portanto, carregadas de características de gênero, raça, classe social e cultural (HARDING, 1996). Tal crítica aponta a passividade dos atributos femininos na fertilização (MARTIN, 1996), a secundarização do citoplasma no desenvolvimento embrionário e da ação materna no ambiente (KELLER, 2006), o dimorfismo e comportamento animal, sobretudo primatologia e evolução (SCHIEBINGER, 2001), a visão androcêntrica da sexualidade e da saúde (MARTINS, 2020) e a exclusão de mulheres ou o silenciamento de suas atividades na história antiga e atual dos círculos científicos (BANDEIRA, 2008).

Desse modo, as pesquisas sinalizam que o conhecimento científico produzido em torno da Biologia é atravessado por normalizações culturais. Assim, argumentamos que, mesmo que não listem conteúdos explícitos de gênero, corpo e sexualidade humana, ainda assim, os currículos de ciências e biologia estão enredados em relações de poder, são permeados de endereçamentos, engendram formas específicas de viver gêneros, corpos e sexualidades. Furtar-se de problematizar como esse conhecimento é produzido, como um campo específico de inteligibilidade é solicitado para falar sobre os corpos, como apenas algumas narrativas são autorizadas, é compor um currículo normativo.

A partir da análise das Unidades Temáticas e de seus respectivos Objetos de Conhecimento e Habilidades, encontramos algumas possibilidades, mesmo não explicitadas no documento, de discussões sobre as temáticas de interesse deste capítulo. Em "Vida e Evolução", para o Objeto de Conhecimento "Programas e indicadores de saúde pública", espera-se o desenvolvimento da habilidade de "Interpretar as condições de saúde da comunidade (ribeirinha, quilombola, indígena e cigana) da cidade ou estado com base na análise e comparação de indicadores de saúde (como taxa de mortalidade infantil, cobertura de saneamento básico e incidência de doenças de veiculação hídrica, atmosférica entre outras) e dos resultados de políticas públicas destinadas à saúde" (p. 501). Há também a habilidade de "Reconhecer a importância do autoconhecimento do corpo do autocuidado e da autoestima como mecanismos importantes para a prevenção e promoção da saúde física e mental da população" (p. 502).

Porém, apenas algumas nuances da saúde são autorizadas e assim, apesar de outras abordagens terem condições para acontecer, não têm espaço indicado. Evidenciamos o não pronunciamento, por exemplo, do pro- 
blema de saúde pública que é o aborto não legalizado ou as condições e ofertas de terapias hormonais para pessoas trans. Esses silenciamento se dá porque o conjunto de saberes disponibilizados pelos discursos biológicos, higiênicos, estatísticos e médicos, pensa a vida cotidiana como uma existência "recoberta pela administração dos corpos e pela gestão calculista da vida" (FOUCAULT, 2010, p. 152). Para permanecerem vivos/as, alunos/as e professores/as são solicitados/as a investigar o ambiente, a alimentação, a saúde, o corpo e a segurança. Ao disponibilizar saberes úteis para se avaliar os riscos, o sujeito é visto como um "empresário de si" em busca de fortalecer o seu "capital-humano" (FOUCAULT, 2008b, p. 311). Como um sujeito apto a viver em seu cotidiano, a pesquisá-lo, a extrapolar os limites espaciais da escola e inserir-se no mundo como um sujeito investigativo, um sujeito da biopolítica (CARDOSO, 2018).

Ao final da trajetória escolar, esse currículo deseja que "tenham condições de serem protagonistas na escolha de posicionamentos que valorizem as experiências pessoais e coletivas, e representem o autocuidado com seu corpo e o respeito com o do outro, na perspectiva do cuidado integral à saúde física, mental, sexual e reprodutiva" (p. 479). No Objeto de Conhecimento "Preservação da Biodiversidade", apresenta a habilidade de "Discutir a evolução e a diversidade das espécies com base na atuação da seleção natural e a seleção artificial sobre as variantes de uma mesma espécie, resultantes de processo reprodutivo e seus impactos na sociedade atual" (p. 507).

O sexo apresentado nesse currículo é o sexo que está a favor da evolução das espécies, posto como sexo natural, normal e perfeito. Um sexo entendido como inerente a todos os seres de qualquer espécie, como algo, portanto, natural e biológico, "expressando as necessidades fundamentais do corpo" (WEEKS, 2010, p. 39). Assim também as práticas sexuais, sob as verdades científicas constituídas, trará normalidade e perfeição aos/às seus/as praticantes. Por entendermos que "através de processos culturais, definimos o que é - ou não - natural; produzimos e transformamos a natureza e a biologia e, consequente a transformamos em históricas" (LOU RO, 2010, p. 11), vemos essa verdade científica sobre o sexo não como algo "'pré-discursivo', anterior à cultura" (BUTLER, 2010a, p. 25), mas sim como uma produção cultural em torno do biológico, como uma construção produtiva. Isto é, o sexo produz efeitos e "ser sexuado é estar submetido a um conjunto de regulações sociais, é ter a lei que norteia essas regulações situada como principal formador do sexo, do gênero, dos prazeres e dos dese- 
jos" (BUTLER, 2010a, p. 143). O sexo torna-se mais que uma característica biológica dada. O sexo é uma categoria reguladora que governa sujeitos. Uma visão reprodutiva e evolucionista sobre os corpos, as sexualidades e os gêneros que está presente em outros currículos, naturalizando padrões e fomentando certas formas de vida, inclusive por técnicas artificiais de seleção de caracteres em embriões (PARANHOS, CARDOSO, 2020).

Para os Objetos de Conhecimento "Mecanismos reprodutivos" e "Sexualidade", são explicitadas habilidades que se relacionam com temáticas de gênero e sexualidade:

Analisar e explicar as transformações que ocorrem na puberdade considerando a formação e atuação dos hormônios sexuais e do sistema nervoso que envolve pessoas e sentimentos que precisam ser percebidos e respeitados.

Comparar o modo de ação e a eficácia dos diversos métodos contraceptivos e justificar a necessidade de compartilhar a responsabilidade na escolha e na utilização do método mais adequado à prevenção da gravidez precoce e indesejada e de Doenças ou infecções Transmissíveis Sexualmente (ITSs).

Identificar os principais sintomas, modos de transmissão e tratamento de algumas DST (com ênfase na AIDS), e discutir estratégias e métodos de prevenção enfatizando a ocorrência das principais DSTs do estado de Sergipe.

Selecionar argumentos que evidenciem as múltiplas dimensões da sexualidade humana (biológica, sociocultural, afetiva e ética) respeitando a diversidade de gênero, de orientação sexual e compreendendo a sexualidade como ampla complexa e íntima (p. 504).

Apesar de permanecer a abordagem higienista acerca da sexualidade que historicamente acompanha as disciplinas ciências e biologia, o currículo estudado abriu possibilidade para aspectos culturais dessa dimensão: transformações na puberdade, o reconhecimento da diversidade de gênero e sexual e, implicitamente, prevenção de abusos. O que não fica claro é o peso do determinismo biológico e engendramento de gênero nessa abordagem quando se discute hormônios, sistema nervoso e sentimentos, contracepção e relações sexuais. Essa preocupação justifica-se no fato de, na educação, os corpos serem convencionados a ganhar contornos de prescrição e homogeneização, anormalizando-se tantos outros modos possíveis, barrando movimentos e trânsitos (VASCONCELOS, CARDOSO, FÉLIX, 2018). Nesse 
sentido, o currículo tem tornado-se "um espaço que busca, o tempo todo, produzir corpos que pesam e que importam", que materializem as normas (PARAÍsO, 2016, p. 210).

\section{Considerações}

Com as análises empreendidas acerca da diversidade no Currículo Sergipano, argumentamos que o documento, produzido a partir da BNCC, mantém uma concepção de diversidade que pouco avança nas questões da diferença e com foco apenas em certas disciplinas. Nesse sentido, destacamos as humanidades como aquelas que apresentam conteúdos que se propõem mais efetivamente desconstruir práticas normalizadoras. Em relação aos saberes biológicos, considerando que estudos indicam um atravessamento normativo no conhecimento científico, ainda argumentamos que há um engendramento de formas específicas de viver gêneros, corpos e sexualidades. As narrativas autorizadas a compor esse currículo, por vezes, restringem-se ao higienismo e à reprodução humana.

Retomamos, então, à questão inicial que mobilizou a pesquisa: a $\mathrm{Bi}$ ologia ainda é o lugar das discussões de diversidade de gênero e sexual? Apesar dos avanços que sinalizamos de pesquisas culturais em outros campos, os saberes biológicos continuam a deter o privilégio na abordagem dessas questões. Ao longo do texto, destacamos brechas que poderiam servir de escape às normalizações e compor outros possíveis, mesmo que não se possa mensurar o determinismo biológico e engendramento de gênero nas abordagens quando o currículo acontece. E isso faz a rede de Educação Básica do Estado de Sergipe compor um grupo que, de certo modo, garantiu as discussões acerca da diversidade de maneira explícita, indo de encontro à BNCC e à onda conservadora que vem assolando o país. Para além desse currículo oficial, como propõem Paraíso e Caldeira (2018), é preciso estranhar, questionar e desmontar as divisões e as hierarquizações de gênero e sexualidade nos currículos das escolas.

Segundo Vianna (2012), a análise de políticas públicas de educação e o contexto no qual elas são produzidas revelam um árduo processo de negociação entre o Estado e movimentos sociais que pressionam por novas políticas públicas, pela ocupação de espaços na administração pública e pelo reconhecimento de novas formas de desigualdade. Como apontaram Cardoso et al. (2019) sobre políticas públicas de currículo nas últimas déca- 
das, apesar da presença de discussões, pouco se problematiza as matrizes discursivas de produção das desigualdades entre grupos, sejam de classe, de gênero, de sexo ou de etnia nos documentos, por isso se tornam frágeis. Recomendam que "é tempo de continuarmos o movimento, de intensificarmos os embates, de somarmos àqueles e àquelas que compartilham o desejo de estranhar o que nos impõem" (p. 1475).

\section{Referências}

BANDEIRA, Lourdes. A contribuição da crítica feminista à ciência. Estudos Feministas, Florianópolis, 16(1): 288, janeiro-abril/2008.

BRASIL. Lei № 9.394, de 20 de dezembro de 1996. Estabelece as diretrizes e bases da educação nacional. Diário Oficial da União: seção 1, Brasília, DF, n. 248, p. 27833-27841, 23 dez. 1996.

BRASIL. Ministério da Educação e do Desporto. Secretaria de Educação Fundamental. Parâmetros Curriculares Nacionais terceiro e quarto ciclos do ensino fundamental: Introdução aos parâmetros curriculares nacionais. Brasília, DF: MEC/SEF, 1998.

BRASIL. Lei № 10.172, de 9 de janeiro de 2001. Aprova o Plano Nacional de Educação e dá outras providências. Diário Oficial da União: seção 1, Brasília, DF, n. 7, p. 1-20, 10 jan. 2001.

BRASIL. Câmara dos Deputados. Centro de Documentação e Informação.

Projeto de Lei do Plano Nacional de Educação (PNE - 2011/2020). Brasília: Biblioteca Digital, Câmara dos Deputados, 2011.

BRASIL. Lei Federal 13.005, de 25 de junho de 2014. Aprova o Plano Nacional de Educação - PNE e dá outras providências. Brasília, DF, 25. Jun. 2014. Disponível em: http://www.planalto.gov.br/ccivil_03/_ato20112014/2014/lei/l13005.htm.

BRASIL. Base Nacional Comum Curricular (BNCC). Segunda versão revista. Brasília: MEC/CONSED/UNDIME, 2016. 
BRASIL. MEC. SEB. 2017. Base Nacional Comum Curricular. Brasília: MEC, 2017.

BRASIL. MEC. Base Nacional Comum Curricular. Brasília, 2018. Disponível em: http://basenacionalcomum.mec.gov.br/images/

BNCC_El_EF_110518_versaofinal_site

BUTLER, Judth. Problemas de gênero: feminismo e subversão da identidade. 3a ed. Rio de Janeiro: Civilização Brasileira, 2010.

CARDOSO, Lívia de Rezende; GUARANY, Ann Letícia Aragão; UNGER, Lynna Gabriella Silva; PIRES, Manuella de Aragão. Gênero em políticas públicas de educação

e currículo: do direito às invenções. Revista e-curriculum, v. 17, n. 4., 2019.

CARDOSO, Lívia de Rezende. Queremos saber, queremos viver: governo do cotidiano no currículo experimental. Currículo sem fronteiras, v. 18, p. 943962, 2018.

CARDOSO, Lívia de Rezende. Produção de corpos e tecnologia de hibridização no currículo experimental. In: 35a Reunião Anual da Associação Nacional de Pós-Graduação e Pesquisa em Educação. 2012, Porto de Galinhas. Anais... Porto de Galinhas: ANPED, 2012. Disponível em: http://35reuniao.anped.org.br/images/stories/trabalhos/GT12\%20Trabalhos/GT122203_int.pdf. Acesso em: 21 set. 2020.

CORAZZA, Sandra Mara. Currículos alternativos/oficiais: o(s) risco(s) do hibridismo. Revista Brasileira de Educação [online]. n.17, Rio de Janeiro, 2001, pp.100-114.

FOUCAULT, Michel. Em defesa da sociedade. São Paulo. Martins Fontes, 2008.

FOUCAULT, Michel. História da Sexualidade I: a vontade de saber. São Paulo: Graal, 2010.

HARDING, Sandra. Ciência y feminismo. Madrid: Ediciones Morata, 1996. 
JUNQUEIRA, Rogério Diniz. A invenção da "ideologia de gênero": a emergência de um cenário político-discursivo e a elaboração de uma retórica reacionária antigênero. Psicologia e Política, São Paulo, v. 18, n. 43, p. 449502, dez. 2018.

KELLER, Evelyn Fox. Qual foi o impacto do feminismo na ciência? Cadernos Pagu. (27), julho-dezembro de 2006 pp.13-34.

LAURETIS, Teresa de. A tecnologia do gênero. In: HOLLANDA, B. H. Tendências e impasses: o feminismo como crítica da cultura. Rio de Janeiro: Rocco, 1994.

LOURO, Guacira Lopes. Pedagogias da Sexualidade. In: LOURO, Guacira Lopes (Org.). $\mathbf{O}$ corpo educado: pedagogias da sexualidade. 3a ed. Belo Horizonte: Autêntica Editora, 2010.

MACEDO, Elizabeth. F.; RANNIERY, Thiago. Políticas públicas de currículo: diferença e a ideia de público. Currículo Sem Fronteiras, v. 18, p. 739-759, 2018.

MARTINS, Ana Paula Vosne. A mulher, o médico e as historiadoras: um ensaio historiográfico sobre a história das mulheres, da medicina e do gênero. História, Ciências, Saúde - Manguinhos, Rio de Janeiro, v.27, n.1, jan.-mar. 2020 p.241-264.

MATOS, Marlise. Teorias de gênero ou teorias e gênero? Se e como os estudos de gênero e feministas se transformaram em um campo novo para as ciências. Estudos Feministas, Florianópolis, 16(2): 440, maio-agosto/2008.

NARDI, Henrique Caetano. O estatuto da diversidade sexual nas políticas de educação no Brasil e na França: a comparação como ferramenta de desnaturalização do cotidiano de pesquisa. Psicologia \& Sociedade, São Paulo, v. 20, n. esp., p. 12-23, 2008.

PARAISO, Marlucy. A ciranda do currículo com gênero, poder e resistência. Currículo sem Fronteiras, v. 16, n. 3, p. 388-415, 2016. 
PARAÍSO, Marlucy A.; CALDEIRA, Maria Carolina. Pesquisas sobre currículos, gêneros e sexualidades. (Orgs.). Belo Horizonte: Mazza, 2018.

PARANHOS, Mayra L. R.; CARDOSO, Lívia de R. Direito de vida e morte em um currículo de Biologia. Educar em Revista. 2020 (no prelo).

PIRES, Manuella de Aragão; CARDOSO, Lívia de R. BNC para formação docente: um avanço às políticas neoliberais de currículo. Revista Série-Estudos. 2020 (no prelo)

RODRIGUES, Tatiane Cosentino; ABRAMOWICZ, Anete. O debate contemporâneo sobre a diversidade e a diferença nas políticas e pesquisas em educação. Revista Educação e Pesquisa, São Paulo, v. 39, n. 1, p. 15-30, jan./mar. 2013.

SCHIEBINGER, Londa. O feminismo mudou a ciência? Bauru, SP: EDUSC, 2001.

SILVA, Tomaz Tadeu da (Org.). Identidade e Diferença: a perspectiva dos Estudos Culturais. 10. ed. Petrópolis, RJ: Vozes, 2010.

WEEKS, Jeffrey. O corpo e a sexualidade. In: LOURO, Guacira L. O corpo educado: pedagogias da sexualidade. 3 ed. Belo Horizonte: Autêntica Editora, 2010 p. 35-82.

VASCONCELOS, Michele Freitas Faria; CARDOSO, Lívia de Rezende; FELIX, Jeane. Por uma educação obscena a desfocar corpos de hipo mulheres. Educação em Revista, Belo Horizonte, v. 34, p. 1-20, 2018. 